\title{
THE MICROCOMPUTER REVOLUTION AND THE ECONOMIC EVALUATION OF COCONUT FARMING SYSTEMS ${ }^{1}$
}

\author{
Dan M. Etherington ${ }^{2}$
}

\begin{abstract}
SUMMARY
Major developments, have taken place in computer technology in the last decade and the rate of change is increasing. Reductions in the size and cost of microcomputers and the availability of vastly improved software can have, a beneficial impact on the speed with which agricultural research is analysed and its imphcations assessed. Examples of software of particular interest to agricultural economists dealing with coconut fanning systems are discussed in the paper.
\end{abstract}

\section{The Continuing Revolution}

The advent of the sihcon chip is having a profound impact on many facets of society in high income countries. Some people view this impact as more profound than the invention of the wheel. The wheel probably had its first applications, in carrying weights and in drawing water in agriculture. The increasing Secondary (industrial) and Tertiary (service) nature of modern society implies that the prime areas of apphcation of new computer technology will continue to be in these sectors. However, the Primary sector, agriculture, is also finding plenty of useful work for the microchip and, in turn, for the microcomputer in measurement, timing and calculation. Currently much of this work in less developed countries (LDCs) is as an aid to research and administration (i).

The microcomputer revolution has resulted in dramatic reductions in cost and size in the physical hardware and in improvements in software (the computer programs). These features signal the end of the 'temple syndrome' that typified the introduction of main-frame computers a generation ago, but do not remove the possibility that this technology itself can become an idol.

There are many measures which show the rapid changes that have taken place in computers. For example, a 1955 IBM 650 cost about US\$200,000, weighed over two tons, required substantial airconditioning and had about $12 \mathrm{~K}$ (that is, 12 thousand characters) of memory. In 1978 a TI-59 Programmable Calculator (similar to that used by Asnawi et al, 1985) cost about US\$300, weighed about $1 / 4 \mathrm{Kg}$ and had about $5 \mathrm{~K}$ of memory. Microcomputers entered the market as kits for the electronics enthusiasts or as 'home computers' -- high technology toys for those on high incomes. Typically these machines had about 12 to $16 \mathrm{~K}$ Random Access Memory (RAM). The first mass-produced complete package of an 8-bit 64K micro, with dual mini-floppy disk drives, monitor and substantial software was introduced (by Osbome) in 1981 for about $\$ 2,000$. Serious business 'desk top' microcomputers costing $\$ 5,000$ to $\$ 25,000$ were in the US market in 1980 starting with 64K RAM and with power exceeding the minicomputers of the mid-70s. At the end of 1981, the giant of the computer industry, IBM, announced its, entry into, the Personal Computer' (PC) market. As a mass-produced 16-bit microcomputer, this has established a new 'industry standard' for single-user situations. What makes the advent of 16-bit (and 32-bit) microcomputers so important is their vastly expanded memory - typically $256 \mathrm{~K}$ or $512 \mathrm{~K}$ RAM plus a floppy disk drive and small Integrated hard disks of 5 to 20 megabytes. Some are truly portable, fit into a briefcase and c6st less than US $\$ 5,000$ (without a printer).

\footnotetext{
${ }^{1}$ If an excuse is needed for this article then a recent issue of Development and Cooperation (No. 3/1985 June/July) devoted to 'Computers and the Third World' provides it in the form of a logo consisting of a coconut tree, a microcomputer and a telephone.

${ }^{2}$ Fellow, National Centre for Development Studies, Australian National University, Canberra.
} 
Cost and size are worth stressing separately not simply be cause of portability, but because their often independent power source and robustness means that ancillary facilities are reduced to a minimum. Temperature tolerances have been raised and power requirements reduced dramatically. An agricultural. research institute no longer needs the costly infrastructure of a special airconditioned building with a 'fail-safe' power supply in which to house a large, sensitive, computer. Equally important, individual components are now compact, light, highly transportable and in modular form so that the expensive 'personnel infrastructure' to maintain a computer is minimised.

These factors mean that the microcomputer has brought powerful measurement an d calculating capabilities to the local research institute level. No longer do statistical and scientific calculations have to be either severely constrained or referred to a national computer 'temple' with lengthy delays betwen the submission of 'prayers' and the receipt of answers. The first article in the first issue of this Journal provides an excellent example of an analysis of a large and important (fertilizer) experiment that was severely constrained, and delayed, by being undertaken with only a programmable calculator (Asnawi. et al. 1985). Such a data set, collected so patiently by researchers over so many years, is a prime candidate for more comprehensive analysis by the researchers themselves in situ.

Equally dramatic advances have been made in the software to match the improvements in computational power. As with hardware, the use of modern software is becoming much less 'skill intensive'. Listings of software designed specifically for agricultural applications run into thousands of programs. Indeed, so much so that there are now directories of the available soft ware (Stilwell, 1983). In addition there are powerful general purpose packages for statistical analysis, word processing, data base management and spreadsheet calculation and graphics. 'Integrated packages' are also now available, incorporating all these facilities. For the agricultural economist, each of these general purpose packages (or the integrated versions) provides a major boon, whether undertaking farm, surveys or maintaining and analysing time-series data sets. A consequence is that the tum around time between data collection, entry, analysis and report writing can be dramatically reduced (2). This is likely to be the major improvement in the 'information flows' to be derived from the microchip by agricultural research institutes through at least the next decade, rather than in the inter-country information flows that so often feature in the discussions of the impact of the micro-processor and its link with satellite communications technology. For the latter purpose, the microfiche is the better (and cheaper) technology (3).

\section{Software for farm budgets}

Producing and analysing farin budgets is one basic task that agricultural economists at agricultural research institutes or Departments of Agriculture often need to undertake and update. In the case of forests, orchards, vineyards plantations and, indeed, tree crops in general, which live for many years, appropriate farm butgets must take account of the long-term nature of such investments. Many coconut land-use systems introduce the added complication of purposely integrating coconut palms with other tree species, annual crops and/or livestock. The purpose of such integration is usually aimed at getting higher productivity by the more efficient use of biological resources, more economic returns, and better social benefits on a sustained basis, than are obtainable from monoculture on the same unit of land. (See Nair 1979, Sefania et al 1982, Fordham 1983, Conway 1985a and b).

This paper now tums to a brief description of a class of general purpose software packages and then to a specialist package, both of which greatly enhance the ease with which farm budgets for coconut fanning systems can be drawn up, analysed and presented for discussion. 


\section{A. Spreadsheets}

A computer 'spreadsheet' starts as a large blank matrix or grid of rows and columns of cells into which data in the form of text, numerical values or equations can be placed (4). Thus one has a large 'scratchpad' in which scalar values or vectors of numbers caii be entered with suitable headings and other notation. Mathematical manipulation of cefls or vectors of numeric values can be undertaken using any of the standard mathematical operators (+, -, x, and /) and many other functions as well. The great advantage of computer spreadsfieets is their flexibility. The spreadsheet matrix can be structured individually for almost any problem involving numbers: from simple personal accounts to detailed sales records and cash flow statements and projections.

Table 1 presents the output from a spreadsheet with the borders included to show the columns (A, B . . . L) and the rows $(1,2 \ldots$. 20). In this; illustrative exwnple, the spreadsheet has been used to recalculate the incremental costs and benefits; of a Clorine fertilizer experiment undertaken by Magat and Padrones (1981). None of the numerical elements shown in bold print was entered physically into the matrix, but was calculated by the spreadsheet by entering simple equations. Thus, column $\mathrm{F}$ was entered as the equation $(\mathrm{E} 14 * 1.5)$ where 1.5 was the copra price in Pesos per kilogram in 1981. This, equation was repeated, by an instruction, for the re st of the column (5). Similarly, each 'incremental change' row was formed by an equation in which an experimental result was subtracted from the Control. Thus row-15 is fonned by (row-14 - row-12). Complex budgets can be formed in this way.

With careful design, changes in key parameters can ripple through a budget to give new results. For example, in Table 1, what if the price of copra were changed to Psl.75? As soon as the 1.5 is changed to 1.75, all the calculated values (shown in bold print) will change. The facility of spreadsheets to quickly answer 'What if . . T questions has been a major selling point. It is, claimed that the original spreadsheet, Visicalc, was the major reason for the initial surge in the purchase of microcomputers. in the United States. New editions of the basic spreadsheet concept have. Many 'bells and whistles' particularly in the fonn of graphical representation of numerical infonnation in 3-D diagrams, bar charts, pie charts, plots and basic statistical measures (means, variances etc).

Thus spreadsheets represent extremely powerful 'scratchpads' that provide an excellent medium for the presentation of farm budgets. The design of a set of spreadsheet equations for a perennial crop problern can take anywhere from a few hours to some months, depending on the complexity of the analysis being undertaken and the skills of the researcher.

However, the very flexibility of a spreadsheet is also a potential weakness: a spreadsheet budget is very much the creation of the individual who builds it. Thus, even if two budgets are built using the same package, containing the same information, and giving the same answers, their structure is likely to be quite different. As a specific application gets more sophisticated it tends to become more rigid and, while it can be modified by another user, it is fair to say that to make other than cosmetic changes requires the new user to have almost the same level of expertise as the designer of the budget. The verification of results, which should always be done, becomes increasingly difficult. Thus, complex spreadsheet analyses tend to 'die', or at least, move on, with their designers. This tendency can be overcome in any specific case by the designer creating a 'template' and 'locking' the design. This must then be carefully documented, with ail the equations used, in some fonn of User's Manual. In essence the template then becomes a special. purpose package but without some of the advantages usually associated with such software.

Although most spreadsheets use English for instructions and help messages, they are more neutral as to the language of input and the output in the sense that text can be entered in any language using Roman script (6). 
Table 1 Sample Spreadsheet Output

\begin{tabular}{|c|c|c|c|c|c|c|c|c|c|}
\hline 1 & B & C & D & $\mathrm{F}$ & G & $\mathrm{H}$ & J & $\mathrm{K}$ & L \\
\hline $\begin{array}{l}2 \\
3\end{array}$ & \multicolumn{9}{|c|}{ Economics of Fertilizer Use Based on $4^{\text {th }}$ year yield (B $\times 8 \mathrm{~m}$ spacing, $156 \mathrm{palms} / \mathrm{ha}$} \\
\hline 4 & 1 & 2 & 3 & 4 & 5 & 6 & 7 & 8 & 9 \\
\hline $\begin{array}{l}5 \\
6 \\
7 \\
8\end{array}$ & $\begin{array}{c}\text { Fertilizer } \\
\text { (Kg per palm } \\
\text { per yr) }\end{array}$ & $\begin{array}{l}\text { Copra } \\
\text { Yield } \\
\text { (Kgs) }\end{array}$ & $\begin{array}{c}\text { Total } \\
\text { Revenue } \\
\text { Ps }\end{array}$ & $\begin{array}{l}\text { Fertilizer } \\
\text { Costs Ps }\end{array}$ & $\begin{array}{l}\text { Other } \\
\text { Costs } \\
\text { Ps }\end{array}$ & $\begin{array}{c}\text { Total } \\
\text { Costs } \\
\text { Ps }\end{array}$ & $\begin{array}{c}\text { Net } \\
\text { Return } \\
\text { Ps }\end{array}$ & $\begin{array}{r}\text { Ber } \\
\text { Ratio }\end{array}$ & $\begin{array}{l}\text { ost } \\
3 / 6^{* *}\end{array}$ \\
\hline 9 & 2 AS (Control) & 2,140 & 3,210 & 562 & 1,156 & 1,718 & $1,492.44$ & .87 & \\
\hline $\begin{array}{l}10 \\
11\end{array}$ & $2 \mathrm{AS}+2.27 \mathrm{PC}$ & 3,308 & 4,962 & 1,331 & 1,435 & 2,766 & $2,196.12$ & .79 & \\
\hline $\begin{array}{l}12 \\
13\end{array}$ & $\begin{array}{l}\text { Incremental } \\
\text { change) }\end{array}$ & 1,168 & 1,752 & 769 & 279 & 1,048 & 703.68 & & 1.67 \\
\hline $\begin{array}{l}14 \\
15\end{array}$ & $2 A S+2 A C$ & 3,839 & 5,759 & 1,170 & 1,587 & 2,757 & $3,001.98$ & 1.09 & \\
\hline $\begin{array}{l}16 \\
17\end{array}$ & $\begin{array}{l}\text { Incremental } \\
\text { change)) }\end{array}$ & 1,699 & 2,549 & 608 & 431 & 1,039 & $1,509.54$ & & 2.45 \\
\hline 18 & $2 \mathrm{AS}+2.22 \mathrm{SC}$ & 2,947 & 4,421 & 803 & 1323 & 2,126 & $2,294.22$ & 1.08 & \\
\hline $\begin{array}{l}19 \\
20\end{array}$ & $\begin{array}{l}\text { Incremental } \\
\text { change))) }\end{array}$ & 807 & 1,211 & 242 & 167 & 409 & 801.78 & & 2.96 \\
\hline
\end{tabular}

* As presented in Magat et al 1981. ** Correct incremental Benefit Cost ratio.

$\mathrm{A} \mathrm{S}=$ Ammonium Sulphate $\left[\left(\mathrm{NH}_{4}\right)_{2} \mathrm{SO}_{4}\right] \mathrm{P} \mathrm{C}=$ Potassium Cloride $[\mathrm{KCl}]$

$\mathrm{AC}=$ Ammonium Cloride $\left[\mathrm{NH}_{4} \mathrm{Cl}\right]$ and $\mathrm{S} \mathrm{C}=$ Sodium Cloride (common salt) $\mathrm{NaCl}$

The 'Incremental changes' ), )), ))) are the differentces from the control.

\section{B. Special purpose software: An Example}

Special Purpose Software, packages for farm budgets lose the flexibility of spreadsheets but should gain considerably in their ease of use for their specific purpose. In particular they should require a much shorter learning period for full competency. They have the big advantage of not being 'user dependent' so that the work of one researcher can easily be passed onto a colleague or successor.

MULBUD is one such specialised computer package (Etherington and Matthews, 1984). It is designed specifically for the economic appraisal of land-use systems involving trees, either as 'sole' enterprises or in combination with other enterprises. The development arose out of attempts to assess optimum intercropping combinations for coconuts in Western Samoa and Sri Lanka. (Etherington 1981, and Etherington and Karunanayake 1981) [7].

Being a specialist design it loses generality but gains in 'user friendliness'and in the sophistication and speed of some of the operations that it is able to undertake. The package gets its name from the fact that it is concerned with multiple enterprises, products, and -timeperiods and provides farm budgets of such systems.

Because of an. initial concern with developing countries, MULBUD has been designed with the expectation that many users will have little or no previous experience of microcomputers and might have minimal training in economics. The intention of the package is to help researchers concentrate on data collection and interpretation, leaving the 'mechanical' tasks associated with the economic analyses (especially the many discounting tasks) to MULBUD. Thus, the program is extremely 'user-friendly', 'fail-safe' and 'obvious'. 
The fundamental building blocks for MULBUD are minimum consistent enterprise data sets which users specify and complete by filling in a form on the computer screen. 'Consistency' requires that inputs, outputs, and prices are defined over the intended period of analysis. Thus users are Torced to incorporate into the dAta set items that are often ignored, such as the distinction between hired and family labour. A crucial. feature of a MULBUD data set is the facility for entering data in terms of 'seasons' (of equal length) over many years. The total number of 'years-timesseasons' must be kept within. the restriction of a total of 200 (60) time-periods using a 16-bit (8-bit) microcomputer [8]. Thus a data set can consist of monthly data for 16 (5) years, or quarterly data for 50 (15) years or annual data for 200 (60) years. It is then easy to build up a 'data base' of many multi-period enterprises. Then, since the data fonn can be recalled at any time to change, or 'edit', the data, modifications can be made to simulate different environmental conditions, price regimes, or cultural practices.

Data sets or budgets are analyses and displayed and/or printed in final. report format tables or charts. These final report tables (10 in all) give information of Labour use, Material Inputs; (fixed and/or variable), Outputs, Assumptions, and Summary and Graphical displays with appropriate economic indicators (Net Present Values, Annuities, Internal rates of return, Benefit/cost ratios etc) and flexible, user-defined, sensitivity analysis (Etherington et al. 1983) [9]. Figure 1 illustrates.the structure of the package, while the headings of some of the tables are set out in an Appendix [10].

Not only does MULBUD encourage the development of a data base of individual enterprises but it also, enables researchers to 'model' whole-farm plans or enterprise combinations. This is achieved by a very simple procedure within the package whereby data sets can be 'scaled', shifted in time and then merged together to simulate a desired temporal and spatial arrangement. These budgets can be designed to conform to land, light, labour and credit constraints. Figures 2 and 3 show in a schematic fashion two contrasting temporal and spatial arrangements for coconuts and cocoa.

Although both temporal models (Figure 2) involve the same enterprises, the timing of the introduction of the cocoa results in very different implications for labour requirements (especially for planting) and in the overall economic results stemming from the cash flow. In a similar way, while biological interactions between enterprises may be crucial, they are rarely known in precise mathematical form. Furthermore, where, they are known it is in a particular environment and it is unlikely to be possible to derive general interaction equations valid for all possible enterprise combinations. This is even less likely for all temporal and spatial arrangements (Figures 2 and 3) in all environments. Experience, fragmentary evidence, hunches and 'guesstimates' of fartners and research teams will be the most likely source of information on these interactions. Use must be made of this information and is done so in MULBUD in three ways: first, by using the built-in Editor to alter data sets appropriately before, building a Multienterprise budget; secondly, by providing specific interaction factors for the use of labour; and finally, by the interpretation given to the sensitivity matrix that is one of the crucial display tables.

Each iteration or 'run' with an individual MULBUD enterprise data set or with a 'model' might be viewed as a bid in an auction in which participants can react and refine their assessments. A series of 'what if ... ?" bids can be made so as to assess the implications of the impact of unknown but possible interactions. Crucial parameters, can be identified through a series of such 'thought experiments' and be the subject of specific research studies. As knowledge of the systems is built up, so ex ante guessti mates can be replaced with ex post measurements. In this way analyses become more refined. Through its extensive editing facilities and sensitivity analysis, MULBUD allows for a rapid series of iterations and, hopefully, steps up a learning curve. Thus, the package may be viewed as an interactive, user-driven, simulation tool giving alternatives, rather than optimal solutions. The design philosophy is very much a cognitive one which seeks to keep the research team at the centre of the 'search' procedure [ii]. 


\section{Figure 1 Program Structure Diagram}

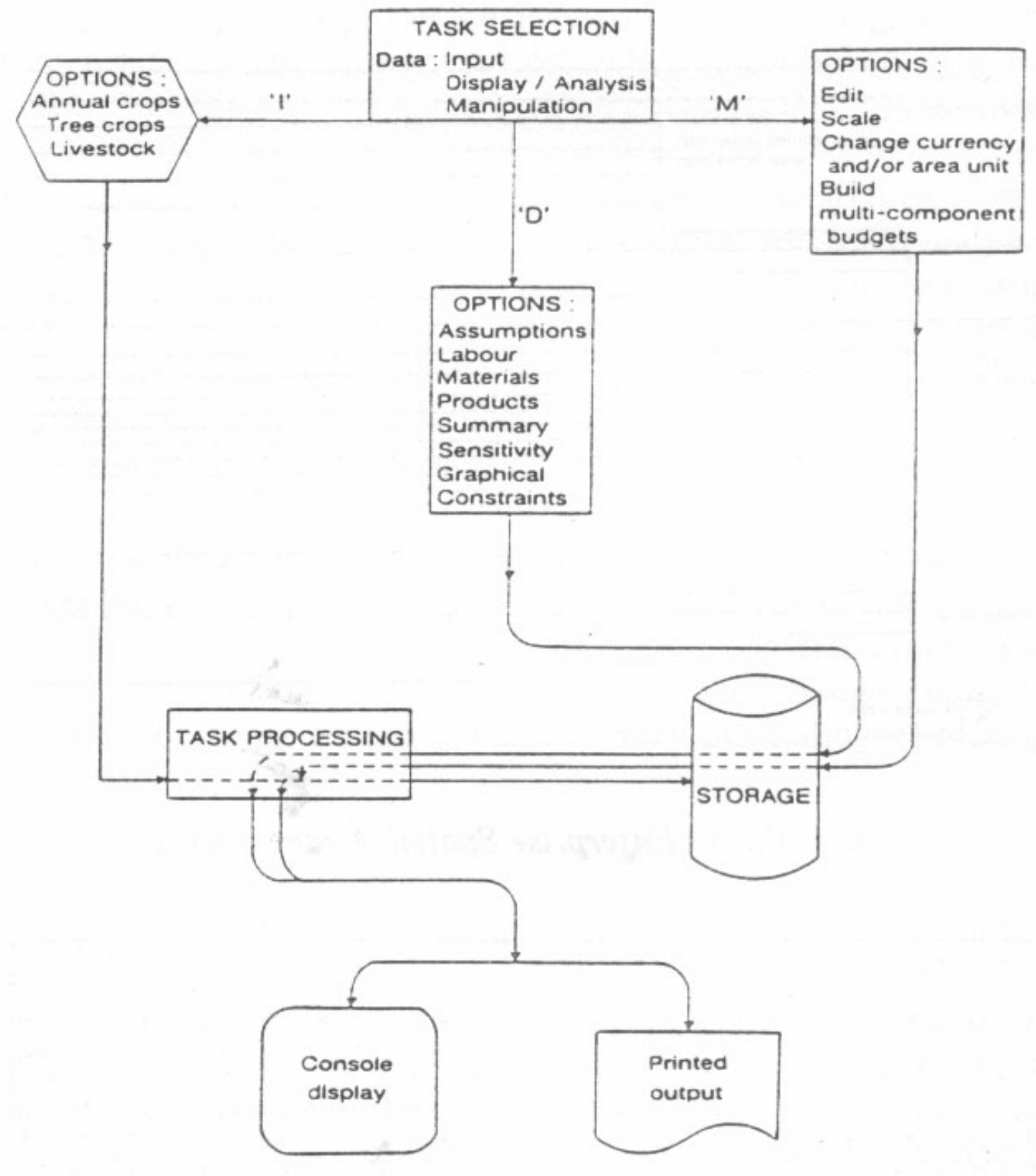




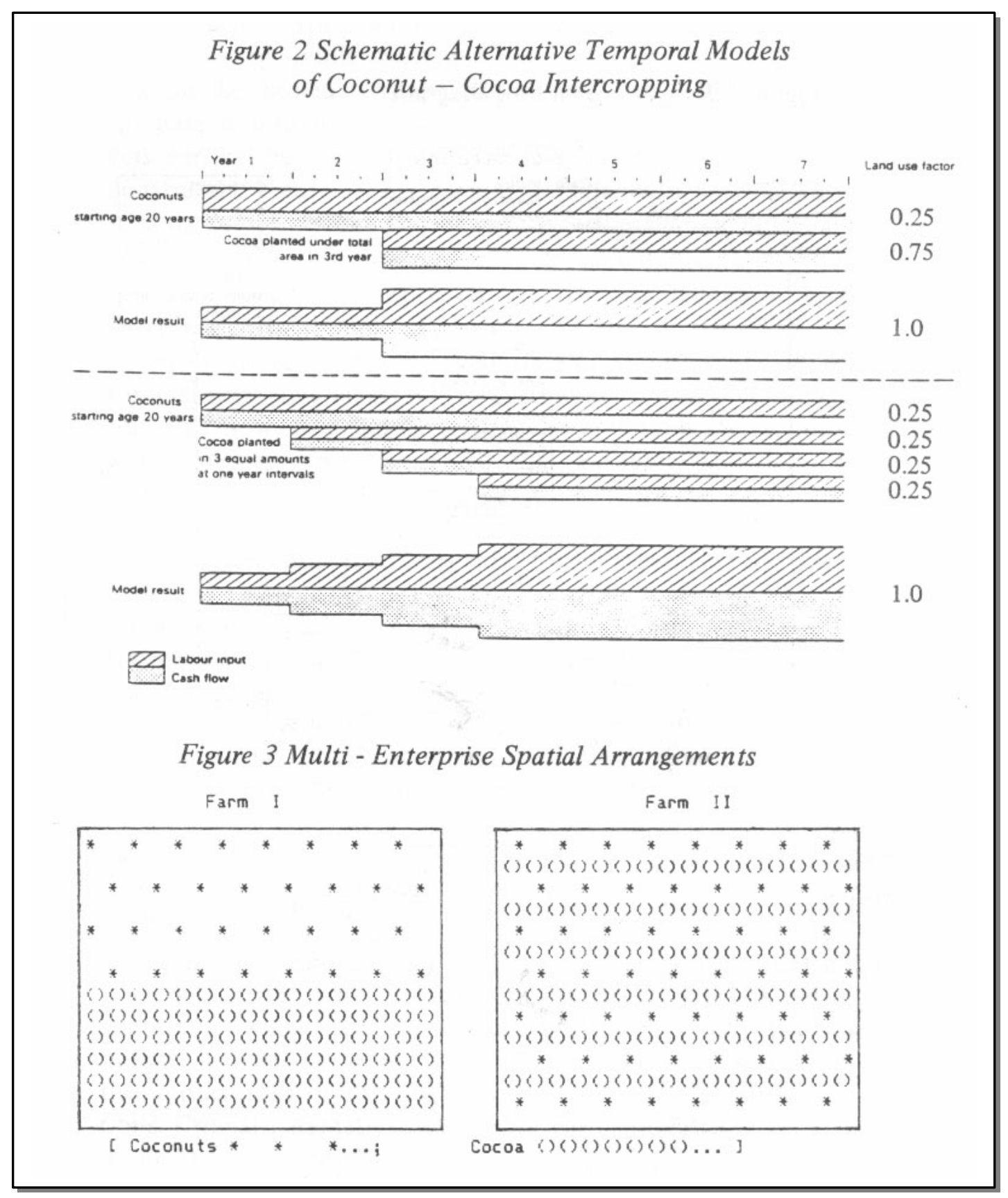


It is necessary, but not sufficient, that economic evaluations of coconut and associated crop projects be undertaken. It is important that they be well done because coconuts and intercropped perennials usually commit farmers to a selected course of action for decades, rather than for one or a few seasons. MULBUD provides a convenient, rapidly leamt, 'slide-rule' for such analyses. Spreadsheets provide a more flexible tool but one requiring higher levels of computational skill. For some users these approaches may be alternatives, but for others they are likely to be considered to be highly complementary. Certainly, these, packages should mean an end to partial budgets of perennial crop farming systems that use either oversimplistic, single-year-at-maturity, budgets, or undiscounted multi-year budgets, or budgets that ignore the seasonality of the production of many tree crops. The budgets that fonn the basis of most economic advice on tree crops, typically have one or more of these drawbacks. Such budgets have the advantage of being simple but can be very misleading. (Etherington, 198 1).

\section{Conclusions}

Microcomputer are no, longer simply the toys of the enthusiasts and the super-rich. The last five years have witnessed their transition to being really effective tools in business and research, partly because they involve only modest computer-specific operating and maintenance skills. They probably provide the most significant 'breakthrough' that has ever occured for enhancing the productivity of scientists at remote agricultural research stations. This is because microcomputers can be used by all disciplines. While not providing a 'technological fix' for rural poverty, the developments in microcomputer hardware and software can speed up research processes. For the agricultural economist, the developments provide the possibility of undertaking far more meaningful evaluations of coconut farming systerns (and tree crops in general) than was conceivable less than a decade ago.

\section{FOOTNOTES}

[1] The term 'microcomputer' is used in this article to refer to the typical small-business or 'professional', 'single-user' desk-top or portable computer consisting of at least $64 \mathrm{~K}$ bytes of Random Access Memory (RAM), two disk drives, a monitor screen displaying 24 lines of 80 characters and with a full-sized, typewriterstyled keyboard. (Typical examples of machines using 8-bit byte processors would include Apple IIe; TRS-80 Models II, 4, 16; Osborne, Kaypro etc. 16-bit machines include IBM-PC, Compaq, DEC Rainbow, TRS 2000 etc). Such a microcomputer plus a printer that prints at least 80 character lines makes up the 'hardware' referred to.No attempt is made in this paper to explain all the computer terminology used. For a very clear introduction and guide, see Wolf (1983).

[2] See Kelly et al 1983 for one annotated bibliography of software for socioeconomic surveys.

[3] Darrow and Saxenian (1985) provide an excellent counterfoil to any suggestion that microcomputers can be or would be the best solution to information gaps (as opposed to computations) in research institutes in developing countries, and they effectively advocate tha use of microfiche.

[4] 'Largr' is a suitably vague description of the size of modern spreadsheets since limitations are usually imposed by the available memory of the particular microcomputer at a particular time rather than by the spreadsheet itself. Typical spreadsheets for 16-bit microcomputers with $256 \mathrm{~K}$ RAM would be able to address 5 to 30,000 cells before memory capacity is exceeded (say 300 rows by 100 columns). 
[5] An advantage of choosing this example is that it demonstrates that taking the ratio of the net benefits to the total costs gives a misleading economic conclusion. The incremental benefits and costs (i.e. compared to the control) correctly show that the Peso spent on common salt gives the highest, and very good, returns. Although the increase in yields is not very great, the cost of the salt treatment is very low.

[6] The implications of the cultural dominance of the Roman script in general and English in particular are undoubtedly very serious (see de Silva', 1981) and will become all the more dominating as the result of the development of computer technology in the West. Nevertheless the technology is moving at such a rate, that translation into local languages and scripts is likely to become easier rather than more difficult. This is the case simply because the binary (zero, one switches) language of computers is culturally completely neutral.

[7] MULBUD was developed at the Australian National University and further development was undertaken in collaboration with the International Council for Research in Agroforestry (ICRAF) in Nairobi with a grant from the International Development Research Centre (IDRC) in Canada. MULBUD is in use in Australia, Canada, Costa Rica, India, Indonesia, Kenya, New Zealand, Papua New Guinea, Peru, Philippines, Solomon Islands, Sudan, Tonga, U.K., and the U.S.A. The matters under investigation then and since have ranged over options for intercropping under coconuts; credit and subsidy policies for banana farmers; the alley cropping of maize and beans between leucaena hedgerows; intercropping of coffee with food crops; silvo-pastoral alternatives in areas suffering orvergrazing; oil palm rehabilitation; and the profitability of peach and Kiwi fruit orchards under different yield, price, and wage rate assumptions.

[8] The numbers in brackets in this paragraph refer to the 8-bit version of the package which requires the $\mathrm{CP} / \mathrm{M}$ operating system. The other numbers refer to the 16-bit version using either MS- or PC-DOS.

[9] Currently the package is only available in English. With the 16-bit version, output can be saved in 'final report formal' so that headings can be modified with a wordprocessor.

[10] In order to save on space, numberical results are only given in the 'Overall Results' table and in the Sensitivity matrix. AR names and units in the headings that are defined by the user in a data set are shown in bold print.

[11] Indeed, this should be the view of the research station towards much rural research (see Conway, 1985 b) as well as in the use of the microcomputer itself. The equipment (hardware and software) is not intelligent and so cannot 'solve' anything. But it can allow users to explore technological altematives that they specify in a highly condensed period of time. (Again, see Darrow et al 1985). 


\section{REFERENCES}

ASNAWI, S. and DARWIS, S. N., 1985. 'The impact of NPKMg fertilizers on smallholder coconut'. CORD Coconut Research and Development (Asian and Pacific Coconut Community). 1 : $1,1-31$.

CONWAY, G. R., 1985 a. 'Agricultural Ecology and Farming Systems Research' in Remenyi, J. V., (ed), 1985.

CONWAY, G. R., 1985 b. 'Agroecosystem Analysis'. Agricultural Administration, 20 : 31 - 55.

DARROW, K. and SAXENIAN, M., 1985. 'Worshipping a False God?' Development: Seeds of Change. 1985:1, 67 - 70.

de SILVA, F., 198 1, 'The Language of the Oracle: English as a Vehicle of Dependency'. Development Dialogue. $1981:$ 2, 165 - 172.

ETHERINGTON, D. M., 1981. Multi-Period Budgeting and the Economic Assessment of Perennial Crop Intercropping; Systems. (The Australian National University, Development Studies Centre, Occasional Paper No. 26). pp. 42.

ETHERINGTON, D. M. and KARUNANAYAKE, K., 1981. 'An economic analysis of some options for intercropping under coconuts in Sri Lanka'. Sri Lanka Journal of Agrarian Studies. 2 : $1.1-25$.

ETHERINGTON, D. M., and MATTHEWS, P. J., 1983. 'Approaches to the economic evaluation of agroforestry farming systems'. Agroforestry Systems. 1: 347 - 306.

ETHERINGTON, D.M., and MATTHEWS, P.J., 1984. MULBUD User's Manual. Canberra: The Australian National University, Development Studies Centre. pp XIV; 96; A- 18.

FORDHAM, R., 1983. 'Intercropping, what are the advantages?'. Outlook on Agriculture. $12: 3,142$ $-146$.

KELLY, V., STEVENS, R. D., STILWELL, T. and WEBER, M. T., 1983. 'An Annotated Directory of Statistical and related microcomputer software, for socioeconomic data analysis'.

Michigan State University, International Development Working Papers No. 12. pp. 165.

NAIR, P. K. R., 1979. Intensive Multiple Cropping with Coconuts in India, Berlin, Hamburg: Parey.

REMENYI, J. V. (ed), 1985. International Farming Systems: Proceedings of a Workshop. Canberra: Australian Centre for International Agricultural Research.

SEFANIA, S., CHANDRA, S., and ETHERINGTON, D. M., 1982. 'A Review of Recent Research on Intercropping Under Coconuts '. Fiji Agricultural Journal. 44 : 1, 31 - 36.

STILWELL, T. C., 1983. 'Softw are Directories for Microcomputers: an Annotated Bibhography'. Michigan State University, International Development Working Papers No. 9. pp 14.

WOLF, C., 1983. 'Guidehnes for the Selection of Microcomputer Hardware'. Michigan State, University, International Development Working Papers No. 13. pp90. 


\section{APPENDIX}

Headings of Selected MULBUD Display Tables

(Elements defined by the user in a data set are shown in bold print)

Enterprise: S.L. New Coconut

Area Unit: Acre

\begin{tabular}{|c|c|c|c|c|c|c|c|c|c|c|c|c|c|}
\hline$* \mathrm{~S}$ & L A & B O & U & & R & Q I & J I I & $\mathrm{E}$ & M F & N T S & Family & & LABOUR \\
\hline Ya & $\mathrm{P}$ & W & $\mathrm{F}$ & $P$ & $\mathrm{P}$ & $\mathrm{O}$ & $\mathrm{H}$ & $P$ & S & Total & Available & $\overline{\overline{ }}$ & $\bar{\nu}$ \\
\hline $\mathrm{r}$ & 1 & $\mathrm{e}$ & $\mathrm{r}$ & s & $\mathrm{r}$ & $\mathrm{t}$ & $\mathrm{r}$ & $\mathrm{r}$ & $\mathrm{e}$ & Labour & & Hired & Family Total \\
\hline $\mathrm{p}$ & $\mathrm{t}$ & $\mathrm{d}$ & $\mathrm{t}$ & $\mathrm{t}$ & $\mathrm{n}$ & $r$ & $\mathrm{v}$ & $\mathrm{c}$ & 1 & & & & \\
\hline & & $\mathrm{La}$ & bou & & & $8 \mathrm{H}$ & $\mathrm{rDa}$ & & & & & Rs & Rs \\
\hline
\end{tabular}

(Where $\operatorname{Prp}=$ Land preparation $;$ Plt $=$ Planting $;$ Wed $=$ Weeding;

Frt $=$ Fertilizer application $;$ Pst $=$ Pest control $;$ Prn $=$ Pruning;

Oth $=$ Other operations; Hrv $=$ Harvesting; Prc $=$ Processing;

and Sel $=$ Selling operations).

Enterprise S.L. New Coconut

* S MATERIAL REQUIREMENTS

$* \mathrm{e}=$

Ya Planting Equipment Fertilizer Chemicals

e s Select Hoes NPK Dolmt Malthn Delqut

a o Nut ea. $\mathrm{Kg} \quad \mathrm{Kg}$ Lrt Ltr.

$\begin{array}{llllll}\mathrm{rn} & \mathrm{Rs} & \mathrm{Rs} & \mathrm{Rs} & \mathrm{Rs} & \mathrm{Rs}\end{array}$

Enterprise: SL Banana (fixed input)
Area Unit: Acre

Total

Additional

Variable

Costs

Material

Variable

Costs

Rs

Rs

\section{ADDITIONAL INPUTS}

$\begin{array}{ll}* \text { S } & \\ * \text { e } & \text { Diesel } \\ \text { Ya } & \text { Electric } \\ \text { e s } & \text { Pum } \\ \text { a o } & \text { Fixed } \\ \text { r n } & \text { item }\end{array}$

r n item

PVC pipe
(roll)
Variable
$\quad$ Rom

Spray

Nozzles

Diesel

Land

Contract

Total

Area Unit: Acre

Fue

Tax

fog

Fixed

spray

costs

Variable

Variable Fixed

Variable Variable

doz

20Lt
Rs acre acre

Rs Rs Rs

Rs 


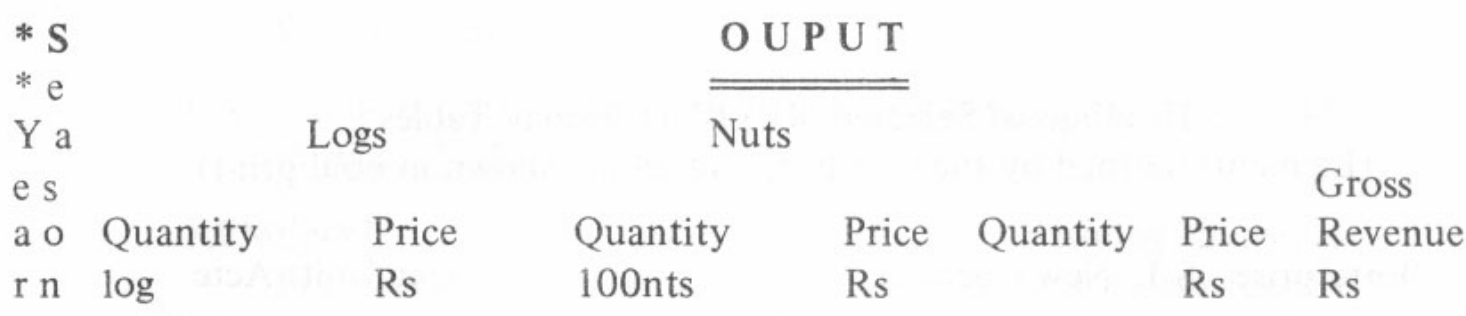

Enterprise: S.L. New Coconut

\section{S U M M A R Y R E S U L T S}

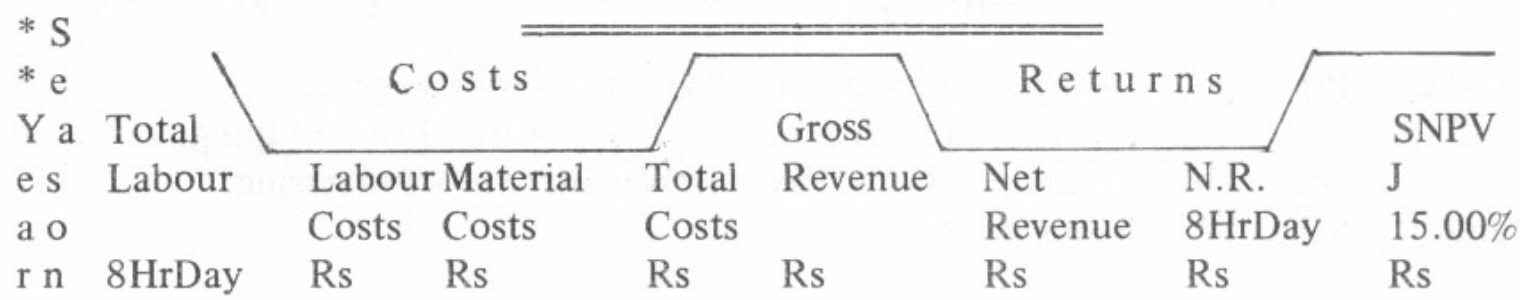

\section{O VER A L L S UM M A R Y}

Enterprise: S.L. New Coconut Item

1. Terminal Value

2. SNPV (J $15.00 \%$

3. Amortized values:

1. (per year)

2. (per season)

4. SNPV/LUI at Maturity

5. SNPV $/ 8$ HrDay

7. Sum of Present Values:
a) Gross Revenue + T.V.
b) Total Costs
c) Material Costs
5800.36
d) Cash Costs
$-3948.50$
$-1939.33$
e) Fixed Costs

3200.00 1851.85

316.69

75.07

7407.40

5.29
6. Labour Use:

Total

Average per year Average per season
8HrDay

349.60

23.30

5.82

8. Benefit/Cost Ratios:

$\begin{array}{ll}\text { [ a ] / : b: } & 1.469 \\ {[2-\mathrm{c}] /: \mathrm{c}:} & 1.955 \\ {[2-\mathrm{d}] /: \mathrm{d}:} & 1.750 \\ {[2-\mathrm{e}] /: \mathrm{e}:} & 0.000\end{array}$




\section{SENSITIVITY ANALYSIS}

Sensitivity Analysis on Discount Rates

\section{Discount Rate} $\%$

8.0

16.0

24.0

32.0
SNPV

Rs

$5,370.15$

$1,563.99$

214.49

$-264.25$
ANNUITY

Rs

627.39

280.51

53.60

$-85.89$

Intemal Rate of Retum is $26.6 \%$

Sensitivity Analysis of Costs and Retums

SNPV in Rs at 15.0 percent per annum

Horizontal axis $=\%$ change in MATERIAL COST

Vertical axis $=\%$ change in GROSS REVENUE

\begin{tabular}{|r|r|r|r|r|}
\multicolumn{1}{c}{$20.0 \%$} & $10.0 \%$ & $0.0 \%$ & $-10.0 \%$ & $-20.0 \%$ \\
\hline $2,624.05$ & $2,817.99$ & $3,011.92$ & $3,205.85$ & $3,399.79$ \\
\hline $2,044.02$ & $2,237.95$ & $2,431.88$ & $2,625.82$ & $2,819.75$ \\
\hline $1,463.98$ & $1,657.91$ & $1,851.85$ & $2,045.78$ & $2,239.71$ \\
\hline 883.94 & $1,077.88$ & $1,271.81$ & $1,465.74$ & $1,659.68$ \\
\hline 303.91 & 497.84 & 691.78 & 885.71 & $1,079.64$ \\
\hline
\end{tabular}

$20.0 \%$

$10.0 \%$

$0.0 \%$

$-10.0 \%$

$-20.0 \%$

(By. MULBUD) 